\title{
El olvido del presente de Dios: Ortodoxia, ideología y populismo religioso desde la filosofía de la religión de Raimon Panikkar.
}

God's present oblivion: Orthodoxy, ideology and religious populism from Raimon

Panikkar's Philosophy of Religion.

\begin{abstract}
Antonio de Diego González ${ }^{\mathbf{1}}$
Universidad Pablo de Olavide, Sevilla, España.

Recibido 15 febrero 2021 · Aceptado 31 marzo 2021
\end{abstract}

\section{Resumen}

Este artículo explora el concepto de ortodoxia que ha suscitado uno de los temas de debate más intensos en Filosofía de la Religión y en la Teología de las principales religiones. Así, partiendo de los planteamientos de Raimon Panikkar se pretende caracterizar de forma sintética la ortodoxia dentro de la experiencia religiosa, su relación con la teofanía, el mito y el rito incluyendo el problema filosófico. Finalmente, reflexionaremos sobre como esta convirtió en populismo religioso y olvidó que el creyente necesita libertad y multivocidad para experimentar lo divino y su propia creencia.

Palabras Clave: Filosofía de la Religión, Ortodoxia, Raimon Panikkar, Símbolo, Populismo

\section{Abstract}

This paper explores the concept of orthodoxy. This has been one of the most intensely debated topics in Philosophy of Religion and also in the Theology of the main religions. Thus, starting from Raimon Panikkar's philosophical approaches, this paper intends to characterize synthetically orthodoxy within religious experience, its triple relationship with theophany, myth and rite, and from the philosophical approach. Finally, this paper reflects on how orthodoxy became religious populism and it forgot that the believer needs freedom and plurality of meanings to experience the divine and his own belief.

Keywords: Philosophy of Religion, Orthodoxy, Raimon Panikkar, Symbol, Populism 


\section{1· Introducción: La ortodoxia como triunfo del signo sobre el símbolo.}

Lo espiritual es inherente al ser humano. Una de las formas en las que podemos definir al ser humano es como homo religiosus. Religado a lo sagrado, el ser humano se construye más allá de la materia, más allá de un lenguaje finito y de su limitada conciencia. La religión y los caminos espirituales han sido, durante toda la historia humana, espacios donde el ser humano ha podido trascender.

Esta es una actividad eminentemente simbólica, es decir, no se agota con la interpretación del sujeto. El sujeto, o los sujetos, pueden volver una y otra vez y no sienten que la experiencia pierda profundidad. Así, la revelación, convertida ya en misterio, se actualiza una y otra vez a través de ritos y mitos. El ser humano crece y va adquiriendo conciencia de un tiempo sagrado y, a la vez, de unas acciones que, incardinadas en ese tiempo, forman parte del camino. Esos símbolos, ya asumidos, dan pie a nuevos a nuevos símbolos y de esa forma la revelación permanece viva y con sentido (Gomez Caffarena, 446-449). Muchas veces en este proceso se corre el riesgo, siendo consecuente con este camino, de acabar convirtiéndose o en un heterodoxo o en un incomprendido en tanto se alcanza un nivel de conocimiento en el que tan solo el silencio puede expresar lo vivido o lo contemplado. Pues más allá de representar una posible impotencia -explica el filósofo y teólogo Raimon Panikkar- este silencio es símbolo de fertilidad y transformación (Panikkar, OC 1, 167-169).

El apofatismo - la asunción de que no podemos tener un conocimiento positivo de lo divino- deja desnudo al creyente de razón o intelecto. Este no tiene más posibilidades que volver al símbolo y entregarse a él por medio del amor o del silencio. ${ }^{1}$ Conceptos ambos que las diversas tradiciones espirituales, desde la bhakti al sufismo o más recientemente la masonería,

1 Quizás el mejor ejemplo de esta situación lo encontremos en la Teología Mística de Pseudo Dionisio Areopagita donde en su primer capítulo se nos invita, previo aviso de no revelarlo a un profano, a negar la posibilidad de conocer a Dios a través de la vía positiva, es decir Dios no es lo que Dios es. Al final no puede expresarse (Pseudo Dionisio Areopagita, 246). 
han potenciado como punto de fuga para la construcción de una antropología trascedente. La gnosis, la ma'rifa o el jñāna son algunos de los términos que recogen el sentido de esta experiencia de (re)conocimiento profundo. En suma, se trata de dar autonomía al creyente y hacerlo consciente de que él es principio y fin de una experiencia trascedente. Una experiencia que supera a los planteamientos exclusivamente intelectuales y mentales.

Esta circunstancia llevó a Raimon Panikkar a reflexionar sobre la manera que estas experiencias espirituales poseen pura libertad en tanto permiten añ sujeto "florecer" escogiendo diferentes posibilidades y eso es lo que, en su opinión, salva al ser humano (Panikkar, Mito, 456-457). La espiritualidad, incluyendo a sus símbolos y a sus ritos, va cargada de libertad y de vida porque no agota su sentido en una sola ejecución. Es el sujeto el que crea el sentido cada vez que ejecuta el ritual o reflexiona/medita sobre los símbolos dados (la palabra revelada, un mándala o un icono).

Al hilo de esto, la historia y las ciencias de las religiones nos muestran que, a la vez que esta experiencia profunda sucede, otro tipo de relación con lo religioso es posible. Aquella en la que prima una intermediación intelectual y una fijación de la teofanía o la revelación como realidad unívoca: la ortodoxia. La palabra ortodoxia, la "correcta creencia", proviene a su vez de los vocablos griegos orthós (correcta, recta) y dóxa (opinión, creencia). La ortodoxia es el triunfo del signo, que es unívoco, y de interpretación limitante ante la realidad simbólica espiritual. En ese sentido la ortodoxia se constituye el triunfo del poder del discurso y el logos frente a la vivencia del sujeto espiritual.

Con carácter ambivalente, la ortodoxia ha llegado a ser un gran aliado de la normalización de la religión en la historia de la humanidad. J. B. Henderson propone en su libro The Construction of Orthodoxy and Heresy (1998) que la ortodoxia es una estrategia de normalización de lo religioso y lo social al generar fronteras entre las creencias y facilidades, dogmático-políticas, para los creyentes. Simultáneamente, la ortodoxia ha abierto las puertas a una progresiva politización y desnaturalización de la experiencia espiritual para transformarla en una ideología religiosa. Esto es visible en la época contemporánea donde cierta lectura de la ortodoxia en religiones como el cristianismo o el islam ha transmutado en un repositorio de poder sociopolítico sobre los creyentes, olvidándose el carácter mul- 
tívoco del símbolo de la experiencia espiritual-trascendente y el poder de la ortopraxis como práctica viva y recuerdo cotidiano de la teofanía.

Un aspecto no menos importante en este debate es la conceptualización histórico-temporal -en el sentido ontológico- que experimenta el creyente. Esto es debido a que la ortodoxia invita a ver la experiencia religiosa desde "un pasado glorioso" (esencialismo) o hacia "un futuro próximo" (mesianismo) haciendo que el sujeto se olvide el "presente de Dios", de la experiencia propia con la teofanía/hierofanía en el lenguaje de Mircea Eliade (29-55). Esta acaba configurándose como una visión con clara vocación de control político que afecta tanto a la moral como a la libertad del creyente reduciendo la experiencia religiosa a un signo unívoco. La correlación entre práctica religiosa, univocidad y la atribución de verdad conduce al extremismo a fin de "proteger" al creyente y a la comunidad, en vez de propiciar un diálogo entre la multivocidad de experiencias religiosas. Y es en este momento donde, a veces, puede operar la violencia intentado mantener el poder político y epistemológico de la ortodoxia sobre los creyentes.

Los fundamentalismos, las inquisiciones, las morales expansivas son, desgraciadamente, cada vez realidades más comunes en un mundo altamente globalizado y universalizado que, paradójicamente, cada vez está más polarizado. Ahí podemos apreciar la enorme crisis de lo religioso en nuestro mundo contemporáneo. Muchos creyentes no comprenden la legitimidad unívoca que intenta proponer la ortodoxia y acaban rompiendo con lo religioso y, en última instancia, con lo sagrado.

Mi propuesta en este texto intenta, partiendo de los planteamientos de Raimon Panikkar se pretende caracterizar de forma sintética la ortodoxia dentro de la experiencia religiosa, su relación con la teofanía, el mito y el rito incluyendo el problema filosófico. Se trata, en última instancia, de una reflexión contemporánea desde la filosofía de la religión con ejemplos del cristianismo, islam e hinduismo sobre como la ortodoxia se convirtió en populismo religioso y olvidó que el creyente necesita libertad y multivocidad para experimentar lo divino y su propia creencia. 


\section{$2 \cdot$ Ortodoxia frente a ortopraxis. La relación con la teofanía, el rito y el mito}

La filosofía de la religión parece haber percibido cierta confrontación entre la ortodoxia y la ortopraxis por la legitimidad de la experiencia religiosa. Una batalla que, ante la aparente victoria de la ortodoxia, ha generado la profunda crisis religiosa de la época contemporánea. Ya que no se trata de un simple problema sociológico o antropológico, sino que su raíz se presenta como un problema filosófico al traspasar las lindes de lo simbólico.

En la cultura de nuestro mundo contemporáneo hay una confusión, bastante común, entre ortopraxis y ortodoxia en relación con el hecho religioso. La ortopraxis, la "recta práctica" (del griego orthós y práxis), es una actitud fundamental en la experiencia religiosa ya que sobre ella pivota el recuerdo simbólico de la teofanía y se amalgaman tanto el rito como el mito. Una triple función indispensable para que el sujeto se sienta parte del juego profundo de lo sagrado. Explicaba Panikkar en Mito, Fe y Hermenéutica que la ortopraxis ni es poíesis (acto de creación) ni es dóxa (opinión), sino una praxis que invitaría a vivir lo sagrado al mismo tiempo que se ejecuta correctamente el ritual (Panikkar, Mito, 215.).

Por su parte, un ritual es un recuerdo de lo sagrado, tanto en tiempo como en forma, no una simple acción aleatoria. Su objetivo es reconocer lo primigenio, recordar la teofanía en cada momento vital humano que para lo Divino es un "eterno presente", un tiempo kairológico. Hacemos ritos al nacer, al crecer, al comer, al morir porque es la adaptación del presente divino al devenir humano. En lenguaje del filósofo de Tavertet el ritual conjuga la heteropraxis (acción de lo divino) con la autopraxis (acción del humano) porque, según dice él: "toda acción que lleve a la perfección del hombre en su situación existencial concreta, toda acción que lleve al hombre a su realización es auténtica praxis o vía de salvación" (Panikkar, Mito, 216). La auténtica ortopraxis excluye, en gran medida, la posibilidad de interpretarlas a través de la opinión (dóxa) o la moral exclusivamente. En este sentido la tradición islámica recoge un dicho autenticado (hadìth șahịḥ) del profeta Muhammad en el que menciona: "Ciertamente las acciones ('amāl) se juzgan por sus intenciones (bi-l niyyāt), así cada hombre tendrá lo que preten- 
día". ${ }^{2}$ Por eso, en el mundo islámico tradicional la ortopraxis es privada y va motivada por la intención (niyya), convirtiéndose en un acto simbólico en base a una acción concreta: rezar, dar una limosna o, por ejemplo, mantener las buenas formas en la mesa. Nadie puede cuestionar la rectitud de la práctica ni tampoco puede "coaccionar en los asuntos del dīn (religión)" advierte el Corán (2:256).

Como he mencionado anteriormente, la ortopraxis recoge el legado de la teofanía, de la revelación. Esta última supone el descenso de una manifestación o de una palabra divina que impactó en el ser humano y su mundo. Muchas tradiciones a estos mensajeros les llaman chamanes, otros profetas, otras creen que sus portadores son seres divinos encarnados. En todas ellas supone el descenso de un mensaje altamente complejo cargado de incomprensión y violencia que rompe el orden establecido y que posteriormente puede convertirse en un camino para llegar a lo divino. Pocos seres acceden a la revelación pura, pero aquellos que acceden tienen que convertirlo en praxis con el fin de poder compartirlo. Una praxis que se acaba convirtiendo en una cotidianización de la revelación que, a su vez, se manifiesta tanto en el rito y en el mito.

Todas las culturas guardan mitos y ritos como auténticos tesoros simbólicos. Ambos son los que activan en los seres humanos la trascendencia, el recuerdo de la revelación. Como bien demostró Joseph Campbell en su libro El héroe de las Mil Caras (2020) la historia del héroe activa en nosotros el recuerdo de algo mucho más profundo que nos conecta con un espacio extra-temporal en nosotros, aquello que Carl Gustav Jung denominaba el inconsciente colectivo (OC 9, § 87-90). Sin embargo, el gran drama de la contemporaneidad es la desconexión, y la no vivencia en última instancia, del rito y por ende del mito como igualmente señala Jung (OC $13 \mathrm{I}$, § 54.) Lo simbólico ha sido sustituido por lo mental, por una hipertrofia de la conciencia (Nante, 43).

El rito se constituye de acciones que sirven para personificar ante nosotros lo sagrado, nos muestra una teofanía distante, pero que manifiesta todo su poder en nuestra cotidianidad. ${ }^{3}$ Nos induce a un tiempo y un 
espacio sacralizado en el cual el sujeto decrece y una conciencia de finitud se apodera de él. Por eso, el rito es terrible y oscuro porque nos muestra la debilidad del sujeto, sus límites. La muerte y el renacimiento se entrelazan y cuestionan la perdurabilidad del sujeto y su conciencia. En el cristianismo es el bautizo y la eucaristía; en el islam es la șalāt (el rezo diario), el dhikr (recuerdo de Allāh) y la peregrinación del Ḥajj; en el judaísmo es la estricta ritualidad cotidiana y los códigos de praxis recogidas en la Mishná; o en el hinduismo son los sacrificios y la meditación. En todos los casos, se exige al sujeto salir de su confort e intentar sacralizar su presente con acciones y formulas que conecten con lo sagrado, que revivan el mensaje de la revelación. En esos ritos se rememora un tiempo presente, un tiempo de Dios, un kairós alejado del mundo temporal, del olvido y de la finitud de la materia. El rito, en la ortopraxis, debe ser vivenciado y hecho suyo por los creyentes y una vez simbolizado en presente conduce a la "libertad de ser" como indica Panikkar (Mito, 29).

Para que esto se produzca, el rito debe transitar hacia el mito, el cual es la cristalización social de la viveza del rito. El mito es un espacio simbólico donde se construye una imagen (eidós) compartida, un ideal fundado en una praxis ritual. El mito, profundamente simbólico, no tiene porque ser verdadero histórica o científicamente porque no se trata de un signo con referencia, sino que su valor es analógico y adaptativo. El ser humano necesita del mito para mitigar la dureza del rito, para poder iniciar un diálogo adaptado con el rito. El diálogo mítico - como lo explica Panikkar- nos invita trascender la razón o la verdad para una comunión simbólica reconociendo la condición de las diferentes experiencias de lo sagrado (Panikkar, Mito, 246). El mito no entiende al logos como absoluto, sino que comprende que es un símbolo para acercarse a algo que excede a ese mismo logos. El mito, igualmente, trasciende la historia y el tiempo profano para delimitar el kairós pero en una mente aún más cotidiana haciendo que el rito tenga sentido y por tanto un recuerdo de una antigua o lejana teofanía.

La ortodoxia irrumpe en este esquema bajo la premisa de esencializar de la verdad, del significado. Así, cuestiona al mito desimbolizándolo, convirtiéndolo en una narración histórica, racionalizada y lógica. En 
sus mejores versiones el rito acaba ante ella como ejecución estética ante el logos (palabra racional) y la dóxa (la opinión). En la versión más extrema el rito es eliminado por inoperante, por anacrónico. Al eliminar esto, la teofanía, la revelación, queda reducida a una especulación racional. La consecuencia directa es que las teofanías son temporalizadas en un tiempo no-kairológico y pierden su carácter de verdad simbólica, su manifestación como un absoluto con muchas visiones y manifestaciones (Panikkar, Mito, 211). La ortodoxia cree y defiende que la verdad debe ser objetivable, unívoca mientras que la teofanía debe ser tan solo un signo unívoco. Dios solo tiene una manifestación y debe coincidir con la ortodoxia.

Derrotado el símbolo y triunfante el signo, la ortodoxia gana control y poder sobre el mito y el rito. Ambos se convierten en meros elementos estéticos - como ya había mencionado anteriormente- que el creyente ya no simboliza, pues el creyente acepta un significado impuesto y en ese momento se elevan fronteras en su mundo espiritual. Da buena cuenta de ello la locución latina Extra Ecclesiam nulla salus (Fuera de la Iglesia no hay salvación), que sirvió de lema no-oficial a la Iglesia Católica durante siglos. Esta frase explicita muy bien el sentido de la ortodoxia pues en su comprensión profunda porque se anula la posibilidad de una misericordia o un amor simbólico más allá del signo y la verdad dada, la metadoxia que menciona Panikkar en Religión y Religiones (OC 2, 96). A veces se usa para asustar, otras para controlar y otras, con algo de buena fe, para "ganar almas". La ortodoxia pretende salvar por encima de lo divino y el misterio, pretende salvar en la tierra pagando un alto precio.

El rito bajo la influencia de la ortodoxia se convierte en una performance mecánica. En el mundo contemporáneo se da buena cuenta de ello pues mucha gente va a la iglesia o a la mezquita sin saber a donde van o que van a realizar allí. ¿Qué significado tiene la comunión si no se vive el misterio de la eucaristía? ¿Qué significado tiene la șalāt islámica más allá de un acto físico-mecánico? El ritual en la ortodoxia no se "vive" como en la ortopraxis pero se "sabe" que es lo correcto. La opinión de ese saber es dada por un núcleo dogmático que ha unido la ideología con lo moral. Se hace por otros y no por sí mismo. La ortodoxia es fundamentalmente comunitarista no comunitaria e, igualmente, identitarista ya que parte de una referencia objetiva de la ideología que lo sostiene (Panikkar, OC 2, 632-633.) Así neu- 
traliza el aspecto simbólico y potencia lo lógico.

La ortodoxia es un fenómeno que no es universal pero gracias a su efectividad goza de gran poder, expansión y legitimidad. El cristianismo, a lo largo de sus veinte siglos de historia, ha elaborado diferentes ortodoxias todas con sus ramificaciones políticas. Por ejemplo, la Modernidad y sus subproductos (nacionalismo romántico, marxismos y todos sus derivados) son ortodoxias dentro de los planteamientos de las ortodoxias cristianas tanto católica como protestante. También hay religiones como el islam que no han gozado de ortodoxia prácticamente hasta el siglo XIX cuando los movimientos reformistas se instituyeron como garantes de la "correcta opinión" (De Diego González, 121). Al mismo tiempo está el paradójico caso del hinduismo en el cual su ortodoxia fue creada desde los planteamientos coloniales británicos y nacionalistas como explica Bryan Pennington Was Hinduism Invented? Britons, Indians, and the Colonial Construction of Religion (2007). Todos con un fin común: establecer un control sobre la espiritualidad. Tras el control doctrinal llega el control político y moral que facilita el control social.

La ortodoxia garantizaba además otro control, este sobre la trascendencia del ritual, ya desimbolizado. El hinduismo nacionalista hidutva emergido de la "reconstrucción" del siglo XIX clama por tener la "auténtica originalidad del ritual sacrificial" frente a la multiplicidad religiosa del subcontinente con cientos de escuelas espirituales que provienen de lecturas individuales o de la mística bhakti. De la misma manera el fundamentalismo islámico y su versión política, el islamismo, afirman poseer la auténtica Sunna del profeta Muhammad. No importa que tanto unos como otros se hayan deshecho del símbolo del sacrificio o la vivencia de la revelación pues para ellos la clave es la esencia que rescatan y mantienen frente a la decadencia, la corrupción de los tiempos y la espera de un tiempo nuevo. Nostalgia por el pasado perdido y mesianismo por el futuro próximo rompen el "eterno presente sagrado" que proponían la teofanía y el rito.

Una vez anuladas las tres realidades simbólicas de la religión-teofanía, rito y mito- la ortodoxia puede tomar el control de lo religioso sin importarle la espiritualidad. Para esta no supone ningún problema que aquel que no case con su dóxa sea expulsado y situado en el margen de la religión. Los heterodoxos, situados en las fronteras y que avisan de los errores de la 
ortodoxia en el mejor de los casos serán desoídos y en el peor reprendidos por la fuerza. Advertía Raimon Panikkar que "el fanático era aquel que ni escucha, ni acepta ni se reconoce cuando el otro habla, es aquel que rompe la comunión mítica y simbólica" (Panikkar, Mito, 255). Y este, sumido en su verdad, no tendrá problema en usar la violencia si llega el caso para defenderla de la herejía. La verdad como signo unívoco, sin posibilidad de lectura solo de veneración, de imposición. Por eso, la violencia es una opción para evitar oposiciones.

Esta relación teológica, y los problemas consecuentes, entre la ortodoxia y la ortopraxis son de sobra conocidos por los estudiosos de las religiones y cuyos efectos sean manifestado a lo largo de la historia a través de herejías, guerras y odio. Sin embargo, habría un problema, quizás de mayor calado, de índole filosófica que no pondría tanto peso en la acción sino más bien en la temporalidad. En mi opinión, el mayor problema de la ortodoxia está ahí en el olvido del "tiempo de Dios".

\section{3- El problema filosófico de la ortodoxia: el olvido del presente de Dios}

El mayor reto que plantea la ortodoxia -desde un punto de vista filosófico- es el olvido del presente de Dios, el olvido de la eternidad. Todos percibimos los efectos sociohistóricos, pero la temporalidad ontológica supone un desafío mayor porque no es el síntoma sino una realidad. Autores como Jung, Campbell o incluso Guénon percibieron el peligro de desconectar la tradición de lo sagrado y convertirla en una pieza de museo alejándola de la vida. Convertir la dimensión simbólica de la escatología en un signo amenaza a la propia existencia humana. Solo desde el símbolo se puede acceder a la parte trascedente porque como advierte Jung: "La aventura espiritual de nuestra época consiste en la entrega de la conciencia humana a lo indeterminado e indeterminable (...)" (Jung, OC 11 I, § 168.).

Las tradiciones espirituales -no necesariamente religiosas en su sentido socio histórico- se vieron en la necesidad de que los sujetos tuvieran que entregarse a lo indeterminable, a un eterno presente que proporcionase un retorno al origen. Especialmente las tradiciones indoeuropeas y semitas hacen hincapié en el concepto de salvación, de trascendencia, de 
presencia en el absoluto. En suma, un vivir el presente de Dios que es objeto de la ortopraxis, equilibrando la soledad, la conciencia de unidad, con la integración en el cosmos, la multiplicidad, según deja entrever en su magna obra The Vedic Experience. Mantramañjarii el propio Panikkar (47).

Gran parte las tradiciones espirituales invitan a sacralizar el presente $o$ a presentificar lo divino en él. Panikkar afirma que en el culto siempre tiene que haber tempieternidad pues no hay tiempo en la experiencia con lo divino, se rompe el tiempo objetivo (Panikkar, Worsphip, 44-45). En mi opinión esto que describe Panikkar es el presente de Dios. El rito no se fundamenta en narrativas (dóxa, logos) ni tampoco lo pretende el mito, pues ambos intentan evocar el tiempo/espacio sagrado aquí y ahora para que descienda lo divino. Puedo ofrecer algunos ejemplos: en una eucaristía cristiana se pretende que Cristo esté presente aquí y ahora para realizar el acto sacrificial, en un dhikr islámico pretende el recuerdo del presente divino en las figuras de Allāh y su Profeta, en un sacrificio hinduista se hace presente el acto de creación del cosmos de Prajāpati o en una ceremonia de santería como un "cumpleaños de Santo" se presentifica a los òrị̀à que son realidades arquetipales con las que la persona con vive. Todos ellos son rituales en tiempo presente y de gran carga simbólica que quieren a lo divino aquí y ahora. El concepto de Dios -en este tipo de experiencias que buscan trascendencia del sujeto- es irrelevante, pues lo que importa es la vivencia del tiempo divino, el ritmo de lo divino (Panikkar, Worsphip, 46-47).

La ortodoxia, sin embargo, desafía a esta percepción porque afirma la opinión (dóxa), a menudo racionalizada, sobre la experiencia. El dogma (lit. enseñanza en griego clásico) pasa a ser un elemento principal frente a la vivencia de la realidad, a la necesidad de libertad para reconectar con el vínculo de lo sagrado. La fe y la ortopraxis del creyente son cuestionadas por la opinión monodóxica (religión como doctrina cerrada) que tiene que ver más con la ideología que con la propia espiritualidad (Panikkar, $O C$ $2,96)$. La ortodoxia religa en tanto realidad social, pero a costa de dirigir la libertad del creyente y cuestionar determinados símbolos de la vivencia espiritual. Y donde más afecta es en el tiempo al convertir el ritual un acto estetizante. Es en ese momento, donde se produce la vivencia de lo sagrado, cambia el presente por el pasado y por el futuro.

La nostalgia del pasado y el futuro mesiánico es el plano tempo- 
ral donde se desarrolla la ortodoxia. Tiempos ontológicos que no reflejan la plenitud de la teofanía sino los devenires del ser humano y sobre todo el triunfo de la teología política. La ortodoxia hipertrofia la memoria y el deseo como elementos de control sustituyendo a la vivencia del presente divino como tiempos de lo religioso. El creyente imbricado en la ortodoxia no se pregunta por sí mismo sino por un pasado glorioso e hiperreal frente a un, aparente, presente decadente frente a la promesa de un futuro glorioso y salvífico. El creyente entonces no vive el rito presente porque anhela otros tiempos o una salvación.

Si bien la salvación es un hecho fundamental en lo religioso, el mesianismo es su hiperdimensión y se complementa perfectamente con la nostalgia. Pero la temporalidad humana no es la divina y ahí se produce un problema. Ni se busca la entrega a lo indeterminado (Jung) ni la vivencia personal (Panikkar) en un tiempo sagrado, sino el recuerdo de otros "tiempos áureos" de cuya caída se culpa al creyente. De esa forma, los garantes de la ortodoxia se apropian del sujeto y prometen salvación. El creyente ya no se salva en el ritual en sí sino en la ejecución comunitaria y política del ritual, en la identificación social y en la racionalización de la fe. Así nacen los dogmas. De igual forma, el mito, atemporal y simbólico, pierde su carga tradicional y se convierte en un signo moral unívoco. Esto da lugar a morales binarias, simplificadas más allá del simbolismo del mito. El siervo ante lo divino, el 'abd de la tradición islámica, deja de serlo para ser siervo ante los hombres de la ortodoxia. La creencia se convierte en doctrina y se esencializa. Así, el dogmatismo, en tanto "justa opinión" sobre esa verdad religiosa, reina sobre los creyentes.

De esa forma, el creyente olvida el presente de Dios, el kairós, para preocuparse excesivamente por el tempus humano. La ortopraxis/tiempo sagrado en presente, cuando en la espiritualidad es indispensable, pasa a ser condición accesoria para darle mucho más peso a la especulación racional/anhelo del creyente. El creyente es contentado con conceptos y performances vacías. También recibe muchas palabras del pasado o promesas para el futuro, pero pocas vivencias del presente y acaba sintiéndose vacío, perdido y olvidado. La vivencia espiritual se museífica, se convierte en un libro más o en una fiesta social y genera gran impotencia que, a su vez, la ortodoxia reviste con obligatoriedad, de pecado, resignificando a la "re-li- 
gación" con lo sagrado. Ahora es "re-ligación" con la comunidad, el poder y la moralidad.

Pero lo cierto es que esta actitud aleja a muchos creyentes, mientras que identitariza y radicaliza a otros. El asunto ya no es experimentar lo divino o la trascendencia sino de la moralidad, del juicio y de la conquista política. Un tiempo que terminará en triunfo solo para los elegidos, donde, a menudo, poco vale la misericordia y el amor. Un tiempo presente maldito que huye asediado por el pasado y el futuro glorioso. Un olvido de un Dios que, en la mayoría de las tradiciones, es considerado tempieternidad e indeterminación. Por todo esto, la ortodoxia olvida el presente de Dios.

\section{4-De la ortodoxia a la ideología religiosa}

La ortodoxia religiosa, a lo largo de los siglos, ha acabado configurándose como una ideología religiosa. Ambas se han hecho complementarias. Al pretender tener una primacía sobre la verdad, el tiempo y la realidad no está dispuesto a compartirlo con nadie. El rito y el mito son privativos del grupo al igual que la fe y la verdad. No hay posibilidades de universalizar y en muchos casos de tolerar. Esto ha conseguido que muchas doctrinas religiosas hayan acabado como ideologías político-religiosa.

El creyente ha transitado la ortodoxia hasta convertirse en sujeto político, en un miembro de la organización y no en un sujeto religioso que busca su libertad. De hecho, la libertad es lo primero que cae en este planteamiento. "¿Para qué quieres libertad? Lo importante es la salvación" se exclamaba a menudo en ciertos ambientes religiosos. Por eso, el filósofo de Tavertet afirmaba que "cuanto más perfecta es una ideología menos tolerante es" (Panikkar, Mito, 51) y esto se debe a que las ideologías llevan muy marcada su "hoja de ruta" moral y política y los seres humanos les importan bien poco. En este planteamiento el ser humano es un agente pasivo y no activo e inserto en una "masa" es prescindible como sujeto libre. Por eso, ese diálogo no puede ser ideología, aunque en ambas haya un logos que opere. En la primera - si se hace bien- el logos va hacia el otro atravesando prejuicios (diá), en la segunda el logos se impone como visión (idéa). La primera nos sitúa como símbolo, dos partes separadas de la misma moneda según su etimología griega, multívoco en los significados. La segunda nos 
la presenta como totalidad indistinta unívoca en cuanto a significados.

La ortodoxia apuesta por la segunda, pues la religión es vista como una idéa frente al símbolo. Una imagen que reverenciar y proteger, como un ídolo, frente a otras interpretaciones y vivencias. Se convierte en un asunto plenamente político y económico para controlar un capital de almas. Por eso, el concepto ideología toma toda su fuerza ya que hay una "hoja de ruta" que cumplir por encima del propio ser humano. De esa forma, la religión se convierte no en un instrumento sino en un fin, y el creyente pasa a ser un número o un cliente al que ofrecerle servicios. Servicios que pueden ser ritualísticos o doctrinales, servicios que se compra-venden sin mayores problemas olvidando tanto las acciones como el tiempo sagrado.

De esa ideología religiosa, con toda su carga moral y política, es muy natural e inmediato que se transite inmediatamente al populismo religioso. En esta ocasión el creyente está tan convencido de su verdad que intenta salvar a otros cueste lo que cueste. En un trabajo anterior definía de esta manera al populismo religioso:

Se trata de imponer a la fuerza una práctica religiosa, que no espiritual, implementando un dogmático sistema moral que suele ir unido a una visión ideológica o política acorde. Para ello, los creyentes se sienten elegidos para hacer llegar un mensaje de "salvación" a otras personas que no lo han solicitado o que no están interesadas en él en virtud de su libertad de conciencia. Sin embargo, tanto el populista religioso como el ideológico piensan que primero la voluntad del pueblo debe cumplirse y debe imponerse, con la única salvedad de que, para el religioso, esa voluntad popular debe concordar con la verdad trascendente y la revelación de Dios. Una verdad aún más difícil de contestar. (De Diego González, 20)

El populismo religioso es un grave problema hoy en día porque amenaza a la libertad colectiva para forzar una visión moral-ideológica y comunitarista de la realidad. No se habla de vivencia espiritual en ningún momento sino de doctrina religioso-política, no se habla de verdades sino de una verdad con mayúsculas. Porque hay una lógica dada por un lógos operando como eje y no por una vivencia subjetiva de lo sagrado. El populismo religioso vence porque la ortodoxia ha restringido la posibilidad de 
que el creyente crea y desarrolle su fe, que lo haga en un marco encauzado y restringido.

Los populistas, en sus diversas formas, juegan a culpabilizar al otro de la incomprensión, de los fracasos morales o de los errores comunitarios. La monodoxia -la identificación de la religión con una doctrina cerrada- de la que hablaba Panikkar se revela en su punto más álgido cuando el grupo se siente amenazado por cualquiera que no participe en la comunión política que la comunidad ha dispuesto. El extranjero, el extraño, el heterodoxo o el hereje no es recibido sino perseguido y culpabilizado de todo lo malo que pueda acaecer al grupo. Y aún el deseo es que otros tomen el camino, lo cumplan y se salven más allá de la voluntad del individuo porque para ellos es Dios el que dicta.

En ese momento la ortodoxia ya no puede hacer nada pues ha sido subsumida por la ideología y el populismo. Lo poco que quedaba de ortopraxis es desdibujado y vuelta a diseñar por la ideología que pretende controlar aun más con el "nuevo rito" que ha perdido todo el sentido originario frente a la teofanía para ser una herramienta de control social. Por ejemplo, las "confesiones colectivas" o el "control espiritual" de algunos grupos ultraconservadores cristianos son buen ejemplo. De la misma manera que la resignificación del culto islámico de los viernes como espacio político en algunas mezquitas de las comunidades islámicas como hizo Khomeini en el Irán revolucionario (De Diego González, 71).

En un ambiente así la ortodoxia puede caer victima del populismo fácilmente y aún más cuando no están claras las fronteras de ortodoxia/ espiritualidad. Este es el caso del islam en el mundo tradicional donde ha habido serías crisis de legitimidad. El islamólogo alemán Ruddiger Seeseman estudió este problema en su libro The Divine Flood. Ibrahim Niasse and the Roots of a Twentieth-Century Sufi Revivalism, que trata sobre la figura y el pensamietno de un importante maestro espiritual senegalés, Ibrahim Niasse (1900-1975). Niasse era criticado por los islamistas y salafistas por estar "fuera de la ortodoxia" y en, no pocos casos, "fuera del islam". El estudio de Seesemann sobre las fuentes primarias y con un análisis profundo de la doctrina concluía, de forma brillante, el riesgo que entrañaba este tipo de juicios porque en el contexto de la tradición Niasse la cumplía y eran los otros, salafistas e islamistas, quienes se habían apartado de la Sunna y el 
Corán que clamaba defender. A juicio de Seesemann la ortodoxia no existía en los planteamientos islamistas y sin embargo, el sufismo al que pertenecía Niasse había sido mucho más fiel en la guarda de la doctrina y en la gestión del derecho islámico que los pretendidos "ortodoxos". Este es un ejemplo del problema que puede suponer superponer ideologías y creencias, que tiene vocación de unívocas y dogmáticas, frente a otras en el terreno espiritual.

El último problema es que estas actitudes populistas, a menudo, conducen a la violencia. Violencia que, por otra parte, conocemos bien a través de su desarrollo histórico porque sus perpetradores dicen que lo hacen en el nombre de la verdad y de Dios. Una violencia que se traviste de religiosa pero que al final es muy terrenal. El fanático religioso no se reconoce, ni escucha ni acepta la idea de la indeterminado-pluralidad de la estructura espiritual como decía Panikkar. El deseo de imponer su verdad le lleva a acallar las voces que no quieran participar en la salvación tal y como la entiende él. Ya sea con una bomba en una clínica de control de la natalidad o inmolándose en la mezquita de una escuela rival. Porque para él, ciertamente, no existe espiritualidad sino política. No ejerce el creyente sincero sino un creyente frágil y débil en quien actúa el miedo como camino hacia su salvación anhelada: el paraíso en la tierra. ${ }^{4}$ Por eso, el radical violento que actúa en nombre de una religión no tiene problemas en usar la violencia y la muerte, la cual considera un deber sagrado para señalar la verdad y la "auténtica" moral representada por las bases de la doctrina enunciada por la ortodoxia. Es la voluntad de Dios que, expuesta de forma unívoca, debe prevalecer sobre los hombres.

En suma, un excesivo sentimentalismo que, anclado en la consistencia de la doctrina ortodoxa, permite dar una falsa seguridad al creyente a costa de eliminar el Misterio, la ortopraxis y la teofanía. Una puerta al totalitarismo y a la perdida de la voluntad. Una voluntad tan necesaria para elaborar un completo camino espiritual según la mayoría de las tradiciones espirituales. 


\section{$5 \cdot$ Conclusiones}

Este trabajo ha expuesto una reflexión sobre la ortodoxia religiosa como problema antropológico, filosófico y, finalmente, sociopolítico. La cercanía que hay con la ortodoxia hace que no tengamos, en muchos casos, suficiente distancia para poder pensarla y ver sus peligros, más allá de virtudes que podemos percibir. El gran problema se presenta en un mundo globalizado, hiperreal -en el sentido que propone Baudrillard- y muy polarizado, en un mundo en el que el esencialismo ha vuelto con fuerza y mucha confianza. Nuestra libertad de conciencia, la gran victoria olvidada de la Ilustración está en peligro debido a un retorno a ideologías fuertes que creen más en el grupo que en el sujeto, que cuestionan la libertad para vivenciar.

Para comprender la ortodoxia, de forma radical, significa volver a comprender las bases de la experiencia religiosa y para ello necesitamos de la antropología. Hace falta volver a la ortopraxis como una base profunda de la experiencia religiosa y comprender su carácter simbólico. Los ritos y los mitos tienen fuerza simbólica para iniciar diálogos profundos, relativizar verdades y encontrar múltiples visiones frente al significado unívoco. No son pocos los autores -como hemos visto con Panikkar y Jung a lo largo de este trabajo- que han advertido de la amenaza de culturas sin capacidad simbólica y hermenéutica.

En nuestros días el problema más popular asociado con la ortodoxia es el político. Es la amenaza más seria porque una vez que la ortodoxia abre el paso a una ideología que totaliza la experiencia religiosa y amenaza por igual al creyente o al no-creyente con una lectura moral de la realidad: o es (bueno) o no-es (malo). Este binarismo puede, a través de un proceso de "sentimentalización" que se da en las políticas populistas como explica Manuel Arias Maldonado en su libro La democracia sentimental (2016), concluir en una radicalización. Un camino en el que se transita fácilmente del populismo al supremacismo ideológico y posteriormente la violencia en poco tiempo. La radicalización violenta encuentra un campo abonado en un espacio tan sumamente sentimental como es una religión ortodoxizada e ideologizada. Un populismo religioso que buscará salvarte aún tú no lo desees.

Pero en mi opinión, el problema más profundo es el filosófico, aquel 
que afecta a la dimensión ontológico-temporal. Pues, ciertamente, de él dimanan los otros anteriores, aunque bien pudiera parecer que son independientes y más urgentes. Se manifiesta en nuestra sociedad contemporánea con una incapacidad intensa para vivir el presente y una sobre presencia del deseo. El deseo de "vivir protegido" es, en definitiva, una cesión de libertad por seguridad que unido a la memoria hacen que el sujeto contemporáneo no sea consciente de su presente para vivir en un pasado glorioso o un futuro salvífico. La ortodoxia sabiendo el poder de control que tenía utilizando esta situación la hipertrofió. El resultado ha sido un olvido del presente como tiempo sagrado, del tiempo de Dios. La ortodoxia ha preferido sacrificar, a lo largo de la historia y en sus múltiples variantes, el tiempo sagrado por la memoria a fin de provocar un poderoso deseo en el creyente y así poder retenerlo en un logos y una moral que se resquebrajan.

La religión y la espiritualidad deberían aspirar a ser herramientas dialógicas, dentro de la inefabilidad de la experiencia espiritual personal, dirigidas hacia la idea de salvación y confort frente al terrible y desconocido absoluto. Esa realidad que que los teólogos de diferentes religiones han denominado: el Misterio. En ningún caso debería convertirse en una ideología que intente manipular y sacar rédito de los seres humanos para obtener prebendas o intereses. Los límites deben humanizarnos y ver al otro un hermano al que ayudar desde la diversidad en la que Dios ha creado como seres humanos según dictan la mayoría de las religiones. Por esa razón Panikkar recomendaba iniciar un "diálogo intrarreligioso" -que da nombre a uno de sus libros más conocidos- antes del diálogo interreligioso (Panikkar, R.: OC 6.2, 31-196), un conocimiento interno previo al conocimiento del otro con el que romper el solipsismo y los prejuicios.

\section{$6 \cdot$ Referencias}

Arias Maldonado, Manuel, La democracia sentimental. Madrid: Página Indómita, 2016.

Campbell, Joseph. El héroe de las mil caras. Vilaür: Atalanta, 2020.

Choza, Jacinto. El culto originario: la religión paleolítica. Sevilla: Thémata Editorial, 2016.

De Diego González, Antonio, Populismo Islámico. Córdoba: Almuzara, 2020. 
Eliade, M.: Tratado de Historia de las Religiones. Madrid: Ediciones Cristiandad, 2006.

Gómez Caffarena, José. El Enigma y el Misterio. Una filosofía de la religión Madrid: Trotta, 2007.

Henderson, John. B. The Construction of Orthodoxy and Heresy. Nueva York: SUNY Press, 1998.

Jung, Carl Gustav. Obras Completas, vol. 9. Madrid: Trotta, 2016.

Jung, Carl Gustav. Obras Completas, vol. 11. Madrid: Trotta, 2016.

Jung, Carl Gustav. Obras Completas, vol. 13. Madrid: Trotta, 2016.

Nante, Bernardo. El libro Rojo de Jung. Buenos Aires: El Hilo de Ariadna, 2011.

Panikkar, Raimon. Worsphip \& Secular Man. Nueva York: Orbis, 1973.

Panikkar, R.: The Vedic Experience. Mantramañjari. Dehli: Motilal Banarsidass Publishers, 1977.

Panikkar, Raimon. Mito, Fe y Hermenéutica. Barcelona: Herder, 2007.

Panikkar, Raimon. Obras Completas, Vol.1.1. Barcelona: Herder, 2015.

Panikkar, Raimon. Obras Completas, vol. 2. Barcelona: Herder, 2015.

Panikkar, Raimon. Obras Completas, vol. 6.2. Barcelona: Herder, 2017.

Pennington, Bryan. Was Hinduism Invented?: Britons, Indians, and the Colonial Construction of Religion. Oxford: Oxford University Press, 2007.

Pseudo Dionisio Areopagita: Obras Completa. Madrid: Biblioteca de Autores Cristianos, 2002.

Seesemann, Rüdiger The Divine Flood. Ibrahim Niasse and the Roots of a Twentieth-Century Sufi Revival. Oxford: Oxford University Press, 2011. 